\title{
La historicidad del espacio
}

\author{
Andrés Núñez ${ }^{1}$
}

Con enorme orgullo y satisfacción entregamos a la comunidad científica este número especial sobre Geografía Histórica. Entre otras razones, lo hacemos porque este trabajo permite poner en valor la relación tiempoespacio que, en general, aparece disociada o en último término idealizada, en un sentido decimonónico.

A través del siglo XIX, el tiempo como elemento central de análisis alcanzó especial importancia cuando, precisamente, la Historia (así con mayúscula, ya que denotaba Espíritu) adquirió un protagonismo inusitado. Fue el momento en que ella se interpretó desde una óptica teleológica, es decir, como fin último o destino, bajo un fuerte influjo hegeliano. De esta manera, la historia se transformó en sinónimo de evolución y civilización y su temporalidad fue lineal. Ello colaboró a comprender o visualizar el espacio como un escenario estático, fijo, inmóvil, es decir, entenderlo solamente desde una perspectiva de naturaleza muerta. Sin embargo, desde mediados del siglo XX, especialmente a partir de la difusión de las ideas posestructuralistas, la importancia que ha ido adquiriendo el espacio como elemento central de análisis, lleva a que su posición se pondere y valorice en las últimas décadas de modo muy diferente. Como ha expresado Foucault: "La gran obsesión del siglo XIX fue, como se sabe, la historia. Tal vez la época actual sea más bien la del espacio". Sin embargo, como él mismo manifestaba, todo espacio tiene una memoria.
En este marco, los valores históricosociales y los significados culturales del espacio, más allá de su realidad física, han ido adquiriendo relevancia en los estudios de la geografía. De este modo, por ejemplo, la fenomenología, un nuevo marxismo o la propia hermenéutica, no han sido indiferentes para el mundo de los geógrafos, generándose impactos directos e indirectos en el desenvolvimiento de la disciplina.

La conciencia de una historia y de un espacio que no es ajeno a las sociedades, hizo cambiar el enfoque. Tal vez el Dasein heideggeriano influyó de modo importante, al marcar la finitud de la existencia. El espacio, desde la geografía, comenzó cada vez con mayor fuerza a comprenderse como temporal, cambiante y móvil, es decir, ya no como un elemento atemporal, neutro, en definitiva, objetivo. Algo similar ocurrió en el campo disciplinar de la historia, cuando se sugirió que la historia también tenía su propia temporalidad narrativa, por lo que el pasado no era ajeno al presente ni a los procesos sociales que influían en aquellas narrativas $y$ procesos interpretativos. En ello, nos parece, la hermenéutica filosófica ha tenido un rol fundamental.

De este giro han dado cuenta numerosas investigaciones entre las que destacan los aportes de Henri Lefebvre, David Harvey, Milton Santos, Denis Cosgrove, Joan Nogué, Yi Fu Tuan, Edward Soja, David Lowenthal, Ives Lacoste, Horacio Capel, todos quienes, en general, han trabajado con fuerza la idea

1 El editor invitado agradece el apoyo de CONICYT, a través del proyecto FONDECYT posdoctoral $\mathrm{N}^{\circ}$ 3110027 (2011-2013), gracias al cual fue posible 
que el espacio y, por ende, el saber geográfico es fruto de procesos socioculturales, evitando con ello una esencialización o naturalización de ambos.

El espacio, en definitiva, ha pasado a visualizarse inserto, como dice Maurice Halbwachs, en los marcos sociales de la memoria, sugiriendo que cada época recrea o reimagina su espacialidad, concluyéndose, por tanto, que la cosmovisión del espacio le pertenece a cada cultura o grupo sociocultural y, en consecuencia, no es posible ostentar una lectura definitiva. Posee, por tanto, textualidades.

Los artículos insertos en el presente número, sin duda, colaboran a madurar o colocar en perspectiva estas cuestiones formuladas con antelación que se vinculan directamente con una geografía histórica cuya base dialéctica de tiempo y espacio le ha permitido posicionarse con fuerza al inicio del siglo XXI.

El primer trabajo de María Laura Silveira, Tiempo y espacio en geografía: dilemas y reflexiones, sirve de marco teórico en la comprensión indisoluble de tiempo y espacio, Ilegando la autora, apoyándose en la tradición filosófica del siglo XX, a formular un asunto tan interesante como profundo como lo es la posibilidad de una Geografía de la existencia.

Enric Mendizábal sustenta su aporte a partir de una pregunta sustancial al inquirir si toda Geografía humana es a su vez histórica. De este modo, expone la necesidad de volver implícita la relación entre historicidad-espacio al momento de hacer geografía. Su texto lleva por nombre precisamente ¿Hay alguna Geografía humana que no sea Geografía histórica?

Por su parte, bajo el título La Geografía histórica, la imaginación y los imaginarios geográficos, Perla Zusman ahonda en una perspectiva, los imaginarios geográficos, que como ella misma resalta convoca cada día a más especialistas. Pero su trabajo da cuenta que su desarrollo, especialmente desde el mundo anglosajón, posee ya varias décadas y que estas nociones han colaborado a madurar el interés por lo social y cultural en el ámbito geográfico.
Pere Sunyer, con su escrito Antroplogía, Geografía histórica y formación del Estado en México, pone en valor la relación indispensable entre geografía y antropología al exponer que la antropología social proporciona otro punto de vista en la construcción del Estado moderno mexicano. En esta línea, sin duda, aporta en la renovación que se viene dando en el vínculo entre geografía y ciencias sociales.

El texto de Carla Lois titulado Isla v/s continente. Un ensayo de historia conceptual, relaciona las categorías de isla y continente trabajando en perspectiva histórica la movilidad con que ellas se han ido representando y, por lo mismo, es una contribución al modo en cómo pensamos nuestras geografías.

Hortencia Castro, a través del artículo La cuestión ambiental en Geografía histórica e Historia ambiental: tradición, renovación y diálogos, lleva a cabo el ejercicio de examinar los aportes realizados sobre la problemática ambiental desde la Geografía histórica, identificando continuidades y rupturas así como los alcances de la Historia Ambiental en el ámbito de la Geografía.

Gerard Jori nos remonta al siglo XVIII para identificar y subrayar el nuevo modo de comprender la problemática sanitaria, momento en el cual ella inició un proceso de institucionalización y racionalización que se vinculó directamente con el poder y la forma de hacer política en la época. Su texto se titula Población, política sanitaria e higiene pública en la España del siglo XVIII.

El trabajo de Rafael Sagredo, denominado Chile en el Cosmos de Humbolt. Conocimiento y saber local para la ciencia universal, también se asienta en la época ilustrada para abordar cómo el saber geográfico de Chile y América meridional se proyecta al mundo a partir de la obra de Alexander von Humbolt, con especial atención en su trabajo Cosmos.

José Ignacio González y Patricio Bernedo proyectan, a través de artículo Cartografía de la transformación de un territorio: La Araucanía 1852-1887, los cambios de representación cartográfica con que la zona de La Araucanía fue ordenándose administrativamente. 
Finalmente, el trabajo de Enrique Aliste y Sofía Pérez, titulado La reconstrucción del Gran Concepción: territorio y catástrofe como permanencia histórica, sigue la línea de algunas de las propuestas precedentes al concentrar su atención en narrativas y discursos en torno a los terremotos de 1939 y 1960 en Chile y cómo a través de ellas es posible visualizar la fragilidad de la memoria social.

Un rasgo común en todos los trabajos es, de allí la relevancia del presente número, que el factor tiempo no aparece disociado del saber geográfico. En consecuencia, son propuestas que invitan a reflexionar en torno a la temporalidad del espacio y a la organización y producción del conocimiento geográfico como resultado de procesos socioculturales.

A los artículos agrupados en la temática Geografía Histórica, le acompañan otros dos de gran interés. El primero se titula Geografía del desierto y turismo de la naturaleza. La revista "En Viaje" y la mirada sobre el paisaje nortino. 1945-1966, de José González y el segundo Urbanização costeira e sombreamento na praia de Boa Viagem, Recife-PE, Brasil, de los autores Rodrigo Mikosz Gonçalves, Admilson da Penha Pacheco, Elmo Leonardo Xavier Tanajura y Luciana Maria da Silva.
El presente número se completa con la sección "Reseñas" donde resalta la inclusión de una entrevista, llevada a cabo por este editor invitado, al destacado geógrafo Alain Musset. En ella el investigador francés plantea varias reflexiones y cuestiones centrales en torno a la problemática central del dossier. El trabajo lleva por título Geografía, Historicidad y Hermenéutica. Conversaciones sobre Geografía con el geógrafo francés Dr. Alain Musset. Acompañan a esta entrevista, los resúmenes de importantes libros. El primero nos remite a la lectura de Cosmos de Alexander von Humboldt, desarrollada por el geógrafo Abraham Paulsen, y la segunda a Observaciones geológicas en América del Sur de Charles Darwin, formulada por el también geógrafo Juan Luis García.

Imposible finalizar sin expresar un último anhelo. Dedicamos este número especial al gran historiador argentino Pedro Navarro Floria, no solo por ser una persona única, de una calidad humana inalcanzable, sino también porque él fue un tremendo ejemplo de la valorización y vínculo de tiempo y espacio como soporte investigativo, y en este contexto, muchos somos deudores de su profundo y sagaz trabajo. 